\title{
A RELAÇÃO ENTRE PRUDÊNCIA E VIRTUDES MORAIS EM GUILHERME DE OCKHAM
}

\author{
Pedro Leite Junior \\ Universidade Federal de Pelotas - UFPel
}

\begin{abstract}
From the statement (admitted by many medieval thinkers) that "there is no moral virtue without prudence, and there is no prudence without moral virtue" the text aims to present Ockham's thesis, according to which the second part of the above statement is not necessary, that is, that there may exists prudence without virtue.
\end{abstract}

KEYWORDS: Ockham, virtues, prudence, connection.

RESUMO: A partir da afirmação (admitida por muitos pensadores medievais) de que "não há virtude moral sem prudência, e, não há prudência sem virtude moral" o texto tem como objetivo apresentar a tese de Ockham, segundo a qual a segunda parte da afirmação acima não é necessária, isto é, pode haver prudência sem virtude moral.

PALAVRAS-CHAVE: Ockham, virtudes, prudência, conexão.

\section{Introdução}

Diferentemente de seus predecessores, como, por exemplo, Tomás de Aquino, Guilherme de Ockham não escreveu um tratado específico sobre ética ou mesmo um comentário a Ethica Nicomachea de Aristóteles. O Venerabilis Inceptor apresenta sua teoria ética de maneira não sistemática, mas através de observações e discussões dispersas por vários de seus escritos. Tal fato, como observa Peter King (King, 1999, p. 227), tem obscurecido a estrutura do pensamento ético de Ockham. No entanto, isso não impede que possamos identificar seu posicionamento no diz respeito a certos temas envolvidos nas discussões éticas. Esse é o caso, por exemplo, da questão 
tradicional que se refere à conexão das virtudes. ${ }^{1} \mathrm{Na}$ obra Quaestiones variae, quaestio VII (Utrum virtutes sint connexae) ${ }^{2}$, Ockham posiciona-se claramente sobre a conexão das virtudes. ${ }^{3}$ A Quaestio VII contém quatro artigos principais, estruturados da seguinte maneira:

(i) No artigo I, Ockham apresenta uma série de conclusões (seis, para ser exato), entre as quais, por exemplo, a questão da origem e geração dos hábitos;

(ii) No artigo II, são estabelecidas várias distinções, dentre as quais se encontram as que dizem respeito aos modos da prudência e aos graus das virtudes;

(iii) No artigo III, Ockham, de fato, aborda de maneira especifica o problema da conexão das virtudes;

(iv) No artigo IV, por fim, ele responde as dificuldades que são colocadas acerca do tema.

Dentre os vários temas abordados na quaestio supracitada, um é particularmente interessante, o qual é objeto desse artigo, a saber, a relação entre prudência e as virtudes morais. Com efeito, Aristóteles na Ethica Nicomachea afirma que:

\begin{abstract}
"Do que se disse fica bem claro que não é possível ser bom na acepção estrita do termo sem sabedoria prática nem possuir tal sabedoria sem virtude moral. E dessa forma podemos também refutar o argumento dialético de que as virtudes existem separadas umas das outras, e o mesmo homem não é perfeitamente dotado pela natureza para todas as virtudes, de modo que poderá adquirir uma delas sem ter ainda adquirido uma outra. (...), pois, com a presença de uma só qualidade, a sabedoria prática, lhe serão dadas todas as outras virtudes. ${ }^{4}$ "
\end{abstract}

\footnotetext{
${ }^{1}$ Acerca da ampla discussão medieval sobre conexão das virtudes, ver, por exemplo, Lottin, 1949. Para uma discussão do tema especificamente em Tomás de Aquino, ver, Hobuss, 2000; em Duns Scotus, ver, por exemplo, Langston, 2008 e Adams, 1996.

${ }^{2}$ As referências às obras de Ockham seguiram doravante o seguinte padrão de citação: Opera Theologicae (OTh), volume, página e linha. OTh VIII, p. 323-407.

${ }^{3}$ Não vou tratar neste artigo sobre a questão da conexão das virtudes em Ockham em sua totalidade, pois meu interesse aqui é mais especifico. Observo, porém, que sobre essa matéria em Ockham podem ser consultados, por exemplo, Suk, 1950 e Wood, 1997.

${ }^{4}$ Ethica Nicomachea VI, 13,1144b30-1145a5. Não é o ponto aqui discutir, especificamente em Aristóteles, a interpretação dessa passagem.
} 
Ora, da passagem acima parece razoável extrairmos a seguinte afirmação (admitida por muitos pensadores medievais): "não há virtude moral sem prudência, e, não há prudência sem virtude moral”; em outras palavras, a virtude moral depende da prudência e a prudência depende da virtude moral, pois uma não se dá sem a outra. Pois bem, a partir desse quadro o objetivo deste texto é apresentar a tese de Ockham, segundo a qual a segunda parte da afirmação acima não é necessária, isto é, pode haver prudência sem virtude moral.

\section{1- A prudência não é uma noção unívoca}

De modo geral, diz-se que uma expressão é unívoca quando é aplicada de uma maneira absolutamente determinada e com o mesmo sentido a diversos sujeitos. Por exemplo, a expressão "planeta" pode ser atribuída de modo determinado e no mesmo sentido (univocamente) a Marte, Vênus e assim por diante. Por sua vez, diz-se que uma expressão é equivoca quando é aplicada a diversas coisas com diversos sentidos. Por exemplo, a expressão "cão" é aplicada a um animal e a constelação, com sentidos completamente diferentes. Há duas boas razões para pensar que a noção de prudência, para Ockham, não é unívoca:

(1) ele apresenta quatro modos nos quais a prudência pode ser entendida;

(2) ele mantém ainda que para cada virtude moral há uma prudência especifica.

Vejamos a seguir cada uma dessas razões.

\section{2- Modos da prudência}

No texto sobre a conexão das virtudes, no artigo II $^{5}$, Ockham faz uma série de distinções (sete precisamente). $\mathrm{Na}$ primeira distinção ele apresenta quatro modos, nos quais a virtude pode ser entendida.

No primeiro $\operatorname{modo}^{6}$, a prudência é entendida como todo conhecimento que dirige uma ação mediata ou imediatamente; e conforme

${ }^{5}$ OTh VIII, $330-340$. 
Ockham é nesse sentido que Agostinho considera a prudência ${ }^{7}$. Dessa perspectiva, a prudência diz respeito a dois tipos de conhecimento evidente:

(i) O primeiro é aquele obtido de uma proposição universal autoevidente (per se notis) por meio do ensino (per doctrinam), ou seja, através de uma operação do intelecto. Um exemplo desse tipo de prudência é expresso pela proposição universal "Todo aquele que age generosamente deve ser tratado generosamente".

(ii) O segundo se refere a uma proposição universal conhecida somente por meio da experiência (per experientiam). Um exemplo desse segundo tipo de prudência é expresso pela a proposição universal "Toda pessoa irada deve ser acalmada com palavras tranquilas”.

De acordo com Ockham, ambos são ciência moral (scientia moralis). ${ }^{8}$ De maneira geral, Ockham divide a ciência moral em positiva e não-positiva. A ciência moral não-positiva é aquela que dirige as ações humanas sem qualquer preceito estabelecido por um superior (caso da ciência moral positiva). Trata-se de princípios conhecidos demonstrativamente ou por si mesmos (per se) ou pela experiência direta deles. Em outras palavras, é o conhecimento que diz respeito a princípios que são evidentemente conhecidos como as conclusões que podemos tirar deles, e assim, podem ser formulados de modo demonstrativo.

Em suma, a prudência no primeiro modo é compreendida como todo conhecimento diretivo, mediato ou imediato, proveniente de proposições universais conhecidas per doctrinam ou conhecidas per experientiam.

No segundo modo9, a prudência é compreendida como todo conhecimento evidente que imediatamente dirige uma ação particular. Nesse sentido, trata-se do conhecimento de uma proposição particular conhecida pelo ensino (per doctrinam), ou seja, pela inferência decorrente de uma

${ }^{6}$ OTh VIII, 330, 3-11: "Uno modo, accipitur pro omni notitia directiva respectu cuiuscumque agibilis vel immediate, sicut Augustinus prudentiam, I De libero arbítrio. Et isto modo tam notitia evidens alicuius universalis propositionis quae evidenter cognoscitur per doctrinam, quia procedit ex propositionibus per se notis, quae notitia scientifica proprie est scientia moralis, quam notitia evidens propositionis universalis quae solum evidenter cognoscitur per experientiam, quae notitia etiam est scientia moralis, est prudentia".

${ }^{7}$ Agostinho, Livre Arbítrio, I, c. 13, n. 27, p. 57: "Considera, agora, se a prudência não te parece o conhecimento daquelas coisas que precisam ser desejadas e das que devem ser evitadas".

${ }^{8} \mathrm{~A}$ respeito da divisão da ciência moral para Ockham ver, por exemplo, OTh IX, 177, 18-28 (Quodlibet, q. 14, p. $177,18-28$.

9 OTh VIII, 330, 14-331, 17: "Alio modo, accipitur pro notitia evidenti immediate directiva circa aliquod agibile particulare, et hoc pro notitia alicuius propositionis particulares quae evidenter sequitur ex universal propositione per se nota tamquam maiori et per doctrinam". 
proposição universal (per se nota). Por exemplo, a proposição particular "João deve ser tratado generosamente" decorre da proposição universal "Todo o individuo que age generosamente deve ser tratado generosamente".

No terceiro modo ${ }^{10}$, a prudência é concebida como todo conhecimento que imediatamente dirige uma ação e é obtido unicamente através da experiência (per experientiam solum), ou seja, tal conhecimento incide apenas sobre proposições particulares conhecidas pela experiência. Conforme Ockham, propriamente falando, esse parece ser o sentido em que o Filósofo ${ }^{11}$ fornece a prudência, pois aqui prudência é distinta da ciência moral. O exemplo de Ockham é a proposição particular: "Este individuo irado deve ser acalmado com palavras tranquilas”. Ora, conhecemos esse modo de agir quer por nossa própria experiência quer pela experiência de outro.

No quarto modo ${ }^{12}$, a prudência é entendida como um agregado de todo o conhecimento diretivo imediato adquirido tanto pelo ensino (per doctrinam) quanto pela experiência (per experientiam). Para Ockham, esse é o tipo de conhecimento que deve ser aplicado a todas as atividades humanas exigidas para o bem viver. Dessa perspectiva, a prudência não é apenas um simples conhecimento, mas inclui tantos conhecimentos quantas são as virtudes requeridas para o bem viver. Por isso, segundo Ockham, toda virtude moral tem sua própria prudência e seu próprio conhecimento diretivo.

Sumarizo os quatro modos da prudência no quadro abaixo:

${ }_{10}$ OTh VIII, 331, 20-26: "Tertio modo, accipitur pro notitia immediate directiva accepta per experientiam solum respectu alicuius agibilis. (...) Et haec notitia est solum respectu alicuius propositionis particulares cognitae per experientiam; et haec videtur esse prudentia proprie dicta secundum intentionem Philosophi, prout distinguitur a scientia morali".

11 Ethica Nicomachea VI, 5-9, 1140a24 - 1142a16.

12 OTh VIII, 331, 27-33: "Quarto modo, accipitur pro aliquo aggregato ex omni notitia immediate directiva, sive habeatur per doctrinam sive per experientiam, circa omnia opera humana requisita ad bene vivere simpliciter. Et isto modo prudentia non est notitia tantum, sed incluit tot notitias quod sunt virtutes morales requisitae ad simpliciter bene vivere, quia quaelibet virtus moralis habet propriam prudentiam et notitiam et notitiam directivam". 


\begin{tabular}{|c|c|}
\hline \multicolumn{2}{|r|}{ Prudência Modo 1} \\
\hline $\begin{array}{l}\text { conhecimento diretivo } \\
\text { mediato ou imediato }\end{array}$ & $\begin{array}{l}\text { Proveniente de proposições universais } \\
\text { (i) Conhecidas per doctrinam } \\
\text { "Todo aquele que age generosamente deve ser } \\
\text { tratado generosamente". } \\
\text { (ii) Conhecidas per experientiam } \\
\text { "Toda pessoa irada deve ser acalmada com } \\
\text { palavras tranquilas". }\end{array}$ \\
\hline \multicolumn{2}{|r|}{ Prudência Modo 2} \\
\hline $\begin{array}{c}\text { conhecimento diretivo } \\
\text { imediato }\end{array}$ & $\begin{array}{l}\text { Proveniente de proposições particulares } \\
\text { (derivadas de proposições universais) } \\
\text { (i) Conhecidas per doctrinam } \\
\text { "João deve ser tratado generosamente" }\end{array}$ \\
\hline \multicolumn{2}{|r|}{ Prudência Modo 3} \\
\hline $\begin{array}{l}\text { conhecimento diretivo } \\
\text { imediato }\end{array}$ & $\begin{array}{l}\text { Proveniente de proposições particulares } \\
\text { (i) Conhecidas per experientiam } \\
\text { "Este individuo irado deve ser acalmado com } \\
\text { palavras tranquilas". }\end{array}$ \\
\hline \multicolumn{2}{|r|}{ Prudência Modo 4} \\
\hline $\begin{array}{l}\text { Agregado de } \\
\text { conhecimento diretivo } \\
\text { imediato }\end{array}$ & $\begin{array}{l}\text { (i) Conhecidas per doctrinam } \\
\text { (ii) Conhecidas per experientiam }\end{array}$ \\
\hline
\end{tabular}

Como veremos mais abaixo, esses quatro modos de compreender a noção de prudência tornam-se importantes no momento em que Ockham os utiliza para estabelecer a relação entre prudência e virtudes morais. No final da exposição acerca dos quatro modos de prudência, Ockham deixa entrever que a prudência não tem uma única noção, ao afirmar que toda virtude moral tem sua própria prudência e seu próprio conhecimento diretivo (quia 
quaelibet virtus moralis habet propriam prudentiam et notitiam et notitiam directivam). Isso nos conduz a verificar a segunda razão da prudência não ser unívoca.

\section{2 Toda virtude moral tem sua própria prudência}

$\mathrm{O}$ artigo III ${ }^{13}$ (Responsio ad quaestionem que aborda especificamente a questão sobre a conexão das virtudes) é composto de quatro sub-artigos:

(i) o primeiro diz respeito à conexão das virtudes morais entre si mesmas;

(ii) o segundo diz respeito à conexão das virtudes morais com as virtudes teologais;

(iii) o terceiro diz respeito às virtudes morais e sua conexão com os hábitos da parte sensitiva da alma; e

(iv) o quarto diz respeito à conexão entre virtudes morais e prudência.

O primeiro sub-artigo (referente à conexão das virtudes morais entre si mesmas) contém sete conclusões. Na primeira conclusão, Ockham afirma que todas as virtudes morais estão conectadas a certos princípios universais, que podem servir como premissa maior e como premissa menor em um silogismo prático proporcionando uma conclusão particular. $\mathrm{O}$ conhecimento dessa conclusão particular é a prudência que imediatamente dirige um ato virtuoso. Para Ockham, o princípio (como premissa maior) é numericamente o mesmo e, posto juntamente com diferentes premissas menores subordinadas, pode servir para provar diferentes conclusões particulares. O conhecimento dessas conclusões são as prudências que dirigem diferentes atos virtuosos. ${ }^{14}$

Podemos exemplificar o que foi dito da seguinte maneira. Da premissa maior "Tudo o que é digno deve ser realizado" conjuntamente com a premissa menor "Ajudar alguém em necessidade é digno" extrai-se a conclusão "Ajudar alguém em necessidade deve ser realizado". Ou, ainda: da

\footnotetext{
${ }^{13}$ OTh VIII, $341-376$.

14 OTh VIII, 347, 141-150: "(...) prima conclusio, quod virtutes morales omnes connectuntur in quibusdam principiis universalibus (...) quae possunt esse maiores et minores in syllogismo practico concludente conclusionem particularem, cuiús notitia est prudentia immediate directiva in actu virtuoso. Et potest idem principium numero esse maior cum diversis minoribus acceptis, sub ad concludendum diversas conclusiones particulares, quarum notitiae sunt prudentiae directivae in diversis actibus virtuosis".
} 
mesma premissa maior "Tudo o que é digno deve ser realizado" conjuntamente com a premissa menor "Visitar alguém doente no hospital é digno" extrai-se a conclusão "Visitar alguém doente no hospital deve ser realizado". Portanto, o conhecimento dessas conclusões são as prudências que dirigem os diferentes atos virtuosos. ${ }^{15}$

Ora, claramente Ockham não parece estar operando com uma noção de prudência unívoca, isto é, uma única prudência que estaria relacionada a cada uma das virtudes morais. Ao contrário, ele afirma que há alguma prudência correspondente a cada uma das virtudes morais, dirigindo-as para um ato virtuoso relativo aquela virtude. Considero que a afirmação de Ockham, segundo a qual há tantas prudências quanto são as virtudes morais, soa um tanto forte; no entanto, observo que ele não está sozinho quanto a isso. Por exemplo, Kent (2006, p. 271) sublinha que de acordo com Scotus é impossível adquirir qualquer virtude moral sem a prudência correspondente; mas cada virtude moral tem sua própria prudência e nenhuma dessas prudências especializadas tem qualquer conexão com as outras. ${ }^{16}$

Expostas as duas razões, pelas quais Ockham parece considerar a noção de prudência como não unívoca, vejamos no que segue como ocorre a relação com as virtudes morais e de que modo ele apresenta a tese de que pode haver prudência sem virtude moral.

\section{3 - A relação entre prudência e virtudes morais}

No artigo III (Responsio ad quaestionem), sub-artigo quatro ${ }^{17}$, Ockham aborda a relação entre virtudes morais e prudência. O sub-artigo é composto por seis conclusões, sendo que: a primeira e sexta conclusão tratam da relação entre virtude morais e prudência; da segunda a quinta conclusão Ockham aborda a relação inversa, ou seja, a relação da prudência com as virtudes morais. É nessas conclusões que aparece a tese de que não é necessário que sempre que haja prudência é preciso haver virtude moral, isto é, pode haver prudência sem virtude moral.

\footnotetext{
${ }^{15}$ OTh VI, 425, 1-426, 3.

16 Penso que o tema acerca das "prudências", tanto em Scotus quanto em Ockham, mereceria uma investigação mais aprofundada, o que neste momento desviaria por demais os propósitos deste texto. Para uma discussão em Scotus, ver, por exemplo, Ingham, 1996.

${ }^{17}$ OTh VIII, 362 - 376.
} 


\section{1 - A relação virtude moral e prudência}

Em concordância com seus predecessores e, em geral, com toda a tradição, Ockham afirma que não pode haver virtude moral e ato virtuoso sem prudência. Pois, nenhum ato é virtuoso a menos que esteja em conformidade com a reta razão (ou prudência). O Venerabilis cita Aristóteles ${ }^{18}$, lembrando que para este a própria definição de virtude contém a noção de reta razão. Na primeira conclusão, portanto, Ockham afirma que todo o ato ou hábito virtuoso requer necessariamente a prudência. ${ }^{19}$

Ockham enfatiza tanto a necessidade quanto a dependência de todo o ato moralmente virtuoso para com a prudência. Essa necessidade diz respeito não somente ao primeiro ato virtuoso, mas também a todos os outros. Nesse sentido, mesmo após ter adquirido um hábito virtuoso, alguém ainda assim necessita da prudência. Todo ato procedente do hábito virtuoso torna-se virtuoso somente quando é estimulado em conformidade com a reta razão (prudência). Caso contrário, tal ato pode ser comparado com aqueles estimulados pelos insanos (fatuis), que podem ter adquirido um hábito virtuoso quando tinham a mente sã. Mas agora em seu estado de fraqueza mental, mesmo aqueles atos que procedem de seus hábitos virtuosos não podem mais ser chamados virtuosos, pois são destituídos de reta razão. Por isso, todo o hábito ou ato virtuoso é direta e necessariamente dependente da prudência. A dependência aqui se refere à relação causa-efeito, ou seja, sem a causalidade eficiente da prudência nenhum ato virtuoso é possível. ${ }^{20}$

Para Ockham, no entanto, a prudência não é única causa dos hábitos e atos virtuosos. Em nosso presente estado e conforme a atual ordem estabelecida por Deus, a vontade também tem um papel indispensável na produção dos hábitos e atos virtuosos. A vontade, como a prudência, é uma causa necessária. Todavia, nem a vontade nem a prudência isoladamente são capazes por si mesmas de produzir um ato virtuoso. A virtude não é um efeito unicamente da prudência nem unicamente da vontade, mas de ambas;

\footnotetext{
${ }^{18}$ Ethica Nicomachea II, 6, 1106b36-1107a2.

${ }_{19}$ OTh VIII, 362, 493-497: “(...) prima conclusio, quod nulla virtus moralis nec actus virtuosus potest esse sine omni prudentia, quia nullus actus est virtuosus nisi sit conformis recta rationi, quia recta ratio ponitur in definitione virtutis /I Ethicorum; igitur quilibet actus et habitus virtuosus necessario requirit aliquam prudentiam".

${ }_{20}$ OTh VIII, 362, 498-500; 363, 510-515: "Et si quaeras utrum post generationem virtutis possit elicit actus virtuosus sine actu prudentiae: respondeo quod non (...) Si quaeras de actu prudentiae, in quo genere causae se habet ad actum virtuosum, ex quo necessario requiritur per se, et effectus sufficienter dependent ex causis essentialibus etc.: respondeo quod est causa efficiens necessario requisite ad actum virtuosum, sine qua impossibile est actum esse virtuosum".
} 
vontade e prudência operam conjuntamente para produzir um efeito comum. Todo o habito ou ato virtuoso é o efeito de duas causas parciais, a saber, a atividade da vontade e a atividade da prudência. ${ }^{21}$

Portanto, no que concerne a relação entre virtude moral e prudência, neste primeiro momento, Ockham não difere da tradição ao afirmar que não há virtude moral sem a operação da prudência. Entretanto, ele não fornece á prudência exclusividade, pois ela é causa parcial e somente conjuntamente com a vontade (que também é causa parcial) é capaz de propiciar o ato e o hábito virtuoso. ${ }^{22}$

Na primeira conclusão, Ockham é taxativo ao afirmar que nenhuma virtude moral pode existir sem algum tipo de prudência. Assim, toda a virtude moral precisa ao menos de um grau de prudência. Entretanto, na sexta conclusão, ele surpreende ao afirmar que algumas vezes as virtudes morais podem existir sem a prudência no primeiro e segundo modo. ${ }^{23}$ Mas, o que Ockham, de fato, quer dizer com isso?

No segundo modo, a prudência é compreendida como o conhecimento diretivo imediato de proposições particulares conhecidas por inferência a partir de proposições universais. Assim, o conhecimento da proposição particular "João deve ser tratado generosamente" é inferido da proposição universal "Toda a pessoa generosa deve ser tratada generosamente". No entanto, agora Ockham refere que o conhecimento do ato a ser realizado (tratar João generosamente) não precisa ser causado (derivado) de uma proposição universal da maneira como é requerido pelo segundo modo. Por quê? Segundo Ockham, o mesmo conhecimento pode ser causado tanto por uma proposição per se notas quanto per experientiam. E, assim, qualquer um dos dois modos é suficiente, pois é possível ter somente o conhecimento dado pela experiência prescindindo do conhecimento da

\footnotetext{
21 OTh VIII, 363, 515-518: "(...) stante ordinatione divina quae nunc est, quia ad actum virtuosum necessario requiritur activitas actus prudentiae et activitas voluntatis, ita quod illae duae causae partiales cum Deo respect actus virtuosi".

22 Suk (1950, p. 105) lembra pertinentemente que essa perspectiva Ockham, acerca do papel da vontade, se separa consideravelmente, por exemplo, da visão tomista segundo a qual a prudência é a principal causa de todas as virtudes; não há outra causa que possa cooperar na realização de um ato virtuoso.

${ }^{23}$ OTh VIII, 375, 800-806: "Sexta conclusio est quod quaelibet virtus moralis potest esse sine prudentia primo modo et secundo modo dicta, quia ad hoc quod actus virtuosus eliciatur, non requiritur quod notitia immediate directiva causetur per propositiones per se notas, quo modo causatur prudentia secundo modo dicta, quia illa eadem notitia potest causari per propositiones per se notas vel per experientiam, et sufficit quod altero illorum modorum causetur".
} 
proposição universal da qual a proposição particular deriva. Por exemplo, um sentimento de gratidão pode levar Manoel a fazer alguma coisa boa para uma pessoa generosa, mesmo que ele não conheça a proposição universal de que devemos fazer coisas boas para pessoas generosas. Em outras palavras, Manoel pode ser grato a seu benfeitor; e, não é necessário que ele conheça a proposição particular "Deve-se ser grato com aqueles que nos ajudam" inferida da proposição universal "Todo o benfeitor merece gratidão". Manoel pode conhecer a proposição particular simplesmente por ter experimentado que este homem particular foi bom com ele. Em suma, é possível adquirir o conhecimento de proposições normativas particulares a partir da experiência, mais do que dedutivamente, e essa forma de prudência não é necessária para a virtude, a menos que seja do modo requerido para a prudência no segundo ou terceiro modo.

Segundo Ockham, o mesmo é válido para o primeiro modo de prudência. Se a experiência pode proporcionar o conhecimento de uma proposição particular, então o conhecimento da proposição universal não é requerido. Todavia, se a experiência não fornece esse conhecimento, então a prudência é requerida no primeiro e segundo modo, mas não no terceiro. ${ }^{24} \mathrm{~A}$ esse respeito escreve Wood:

\begin{abstract}
"Embora a virtude moral não requeira conhecimento moral universal, ela requer o conhecimento particular, quer adquirido pela razão (segundo modo) ou pela experiência (terceiro modo). Não há virtude sem prudência e isso deve ser especifico. Se a razão falha, a experiência é necessária; na ausência da experiência, a razão é requerida. Ockham sugere que algum grau da prudência no terceiro modo realmente é necessário. Ele diz que embora seja teoricamente possível levar uma vida virtuosa somente baseada em princípios particulares
\end{abstract}

\footnotetext{
${ }_{24}$ OTh VIII, 375, 810-376, 819: "Sed ad hoc quod actus virtuosus eliciatur, necessario requiritur prudential secundo modo vel tertio modo dicta. Et eodem modo, ad virtutem moralem non requiritur prudentia primo modo dicta, quia ut patet, notitia particularis cuiuscumque immediate directiva potest haberi per experientiam, ad quam non requiritur notitia alicuius universalis. Si tamen notitia evidens alicuius particularis non posset haberi per experientiam, tunc virtus illa, cuiús notitia particularis esset directiva, riquereret necessário prudentiam primo modo et secundo, sed non tertio".
} 
racionalmente derivados de princípios universais, de fato, não há substituto para a experiência. ${ }^{25}$ "

\section{2 - A relação prudência e virtude moral}

A partir da segunda conclusão, até a quinta, Ockham coloca em prática as distinções realizadas anteriormente quanto aos modos de se entender a noção de prudência. $\mathrm{Na}$ verdade, ele relaciona cada um dos modos com as virtudes morais fazendo surgir a tese de que não é necessário que sempre que haja prudência é preciso haver virtude moral, isto é, pode haver prudência sem virtude moral.

No início da segunda conclusão Ockham afirma que a prudência em seu primeiro modo (conhecimento obtido a partir de proposições universais per doctrinam ou per experientiam) pode existir independentemente de qualquer habito ou ato virtuoso. ${ }^{26}$ Por exemplo, João pode ter o conhecimento da proposição "Tudo o que é digno deve ser realizado", e através de um ato do intelecto inferir a conclusão "Isto que é digno deve ser realizado" (lembremos que o conhecimento dessa conclusão é a prudência). Mas, ainda que João tenha o conhecimento dessa conclusão, mesmo assim ele pode ficar inativo e não querer colocar esse conhecimento em prática. Por isso, em seu primeiro modo, a prudência não precisa ser seguida por um habito ou ato virtuoso, ou seja, o conhecimento dessa conclusão, que é a prudência, não necessariamente dirige para um ato virtuoso. Mas, qual a razão disso?

Ockham sustenta que um ato do intelecto (o de fazer uma inferência, por exemplo), isoladamente, não é capaz de promover um ato intrinsecamente virtuoso. ${ }^{27}$ Pois, um ato verdadeiramente virtuoso unicamente é obtido pela operação conjunta do intelecto e da vontade. No entanto, a vontade não obedece necessariamente o ato do intelecto, dado que: ela pode discordar dele; ela pode mesmo escolher o oposto do que o intelecto

\footnotetext{
25 Wood, 1997, p. 251.

${ }^{26}$ OTh VIII, 363, 521-522: "Secunda conclusio est quod prudentia primo modo potest esse sine omni actu virtuoso et habitu". Ockham expõe uma extensa série de argumentos para comprovar essa conclusão. Subjacentes a todos eles está sua intenção de garantir a liberdade da vontade em obedecer ou não os ditames da reta razão.

${ }^{27}$.No artigo I, terceira conclusão (OTh VIII, p. 327-328), Ockham define o que é um ato intrinsecamente virtuoso.
} 
propõe; e pode ainda suspender completamente seu ato. ${ }^{28}$ Isso porque, para Ockham, a vontade é absolutamente livre e não pode ser determinada por algo fora de si mesma, nem mesmo pelo intelecto. ${ }^{29}$ Ora, se a vontade não fosse absolutamente livre, seu modo de operar não seria diferente daquele dos atos dos apetites sensitivos, que sempre seguem a apreensão sensitiva. Consequentemente, a vontade não seria livre e não poderia ser recompensada ou punida por suas ações. ${ }^{30}$

É nesse sentido que todos os atos do intelecto, imediata e necessariamente quando outro ato é posto, não podem ser considerados verdadeiramente virtuosos. Mas na medida em que a vontade aceita o que proposto pelo intelecto, então ambos conjuntamente produzem um ato bom e intrinsecamente virtuoso, ou quando a vontade escolhe aquilo que é oposto à reta razão, então resulta um ato intrinsecamente mau da vontade.

É a vontade e não o intelecto, portanto, o fator decisivo com relação a hábitos e atos virtuosos. Todavia, a vontade nunca age independentemente do intelecto. Se a vontade age em conformidade com a reta razão, então resulta um ato virtuoso; ou se age contra a reta razão, então resulta um ato mau. Por esse modo de operar (absolutamente livre) a vontade difere do intelecto e, por isso, a prudência em seu primeiro modo pode ocorrer sem habito ou ato virtuoso. ${ }^{31}$

$\mathrm{Na}$ terceira conclusão, Ockham declara que a prudência em seu segundo modo (conhecimento de uma proposição particular obtido através da inferência, per doctrinam, de uma proposição universal) também pode existir sem virtude moral. ${ }^{32}$ Por exemplo, o intelecto pode propor uma proposição particular à vontade, tal como: "Este bem deve ser realizado", obtido por meio da inferência

${ }^{28}$ OTh VI, 421, 16-18 (Sent. III, q. 12): “(...) voluntas potest discordare a ratione et velle oppositum. Potest etiam omnem actum suspendere".

${ }^{29}$ Acerca da controvérsia sobre a liberdade da vontade em relação aos atos diretivos do intelecto, ver, por exemplo, Cristóbal-Sebastián, 1958.

${ }^{30}$ De acordo com Ockham, artigo I, quarta conclusão (OTh VIII, 329, 132-143) somente um ato da vontade pode ser louvável ou condenável.

31 OTh VIII, 363, 523 - 364, 532: "(...) ille actus qui necessario conformatur alteri et qui de necessitate ponitur altero posito, non est primo virtuosus formaliter. Hoc patet, quia ille actus qui necessário conformatur alteri, non est primo laudabilis, nec propter illum laudamur nec vituperamur. Patet etiam per exemplum de actu appetitus sensitivi, qui necessário pomitur posita apprehensione sensitiva; ideo non est primo laudabilis. Sed si actus virtuosus necessário poneretur posita recta ratione, necessário conformaretur sibi, et sic ille actus non esset primo virtuosus sed actus intellectus, cuiús oppositum est prius probatum".

32 OTh VIII, 371, 691-695: "Tertio conclusio est quod prudential secundo modo dicta, pro notitia immediate directive alicuius particularis evidenter illatae ex universali, potest esse sine virtute morali. Haec probatur per easdem rationes per quas prior probatur, quia dictante intellectu de aliquo in particular, potest voluntas in contrarium etc". 
da proposição universal "Todo o bem deve ser realizado". A vontade, por sua parte, pode seguir o que é proposto pela reta razão e assim fazendo ter como resultado um ato virtuoso. Porém, na medida em que é absolutamente livre, a vontade não é forçada a seguir o ditame da reta razão, mas tem o poder de fazer justamente o contrário. Por exemplo, Diego é um individuo incontinente que conhece a proposição universal: "Tudo o que não é honrado deve ser evitado". Além disso, a partir da experiência, Diego sabe que o adultério também não é honrável. Tendo as premissas, ele já não pode ignorar a conclusão, a saber, "O adultério deve ser evitado". Contudo, apesar desse conhecimento ele escolhe o contrário. Por isso, a prudência em seu segundo modo (enquanto uma atividade inferencial do intelecto) pode existir sem um habito ou ato virtuoso correspondente. Ela permanece estéril se a vontade não aceita seus propósitos. Mas, na medida em que a vontade coopera e segue o julgamento racional, então o ato virtuoso é imediatamente produzido. ${ }^{33}$

$\mathrm{Na}$ quarta conclusão, Ockham assevera que a prudência tomada em seu terceiro modo (conhecimento de proposições particulares, obtido unicamente per experientiam) pode, por meio da experiência dos atos de outros, existir algumas vezes sem virtude moral; todavia, o conhecimento obtido pela própria experiência do ato é necessariamente seguido por alguma virtude moral. ${ }^{34}$

Por exemplo, o conhecimento da proposição "Um individuo irado dever ser acalmado com palavras dóceis” é obtido através da experiência dos atos de outro e não é necessariamente seguido por um ato virtuoso. Pois, algumas vezes acontece que alguém conhece a validade da proposição e mesmo assim em um determinado caso não agir de acordo. Dessa perspectiva, a prudência no terceiro modo não é necessariamente seguida por um habito ou ato virtuoso.

Por outro lado, segundo Ockham, a proposição "Aquele que é temperante torna-se mais disposto a adquirir um grande conhecimento e o amor de Deus", cuja validade apenas pode ser conhecida por meio da

${ }^{33}$ OTh VIII, 371, 702-709: “(...) quando aliqua sic se habent quod posito primo, necessario ponitur secundum, impossibile est primum poni nisi ponatur secundum, et per consequens secundum non est in potestate voluntatis nisi quia primum est. Sed recta ratione dictante quod aliquid sit omnino operandum, et voluntate volente efficaciter illud operari, necessário operatur et exsequitur secundum potentias exteriores, si non impediatur; igitur necessário sequitur imperium exsecutionis".

${ }^{34}$ OTh VIII, 372, 736 - 373, 740: "Quarta conclusio est quod aliqua prudentia tertio modo dicta potest esse sine virtute morali, et aliqua non. Hoc patet, quia aliqua talis propositio potest cognosci per experientiam acceptam respectu actus alterius hominis, aliqua non potest evidenter cognosci nisi per experientiam acceptam respectu proprii actus". 
experiência do próprio ato, não pode ser conhecida a menos que esteja em imediata conexão com uma virtude moral, pelo menos na medida em que o primeiro ato virtuoso está em causa. Pois, embora adquirindo o conhecimento dessa proposição, alguém tem que ser temperante por um determinado período de tempo e esses atos contínuos de restrição às paixões desordenadas necessariamente produz o habito da temperança. Assim, quando alguém conhece essa proposição, necessariamente adquire também uma virtude moral. Contudo, ainda que esse conhecimento seja adquirido, pode ocorrer que ele permaneça sem ser acompanhado por uma virtude moral. Portanto, esses fatos confirmam a conclusão de que a prudência, em seu terceiro modo, pode existir com ou sem virtude moral.

Por fim a quinta conclusão encerra a relação entre prudência e virtudes morais. Ockham toma a prudência no quarto modo, que inclui o conhecimento diretivo de todas as virtudes necessárias para conduzir a uma vida perfeita. Trata-se de algo como um agregado de todas as classes precedentes de prudência; como tal, certas virtudes morais devem acompanhá-la enquanto outras podem estar ausentes. ${ }^{35}$

Por exemplo, João pode ter conhecimento de proposições universais ou conclusões particulares per doctrinam ou per experientiam sem ter a virtude correspondente. Mas João não pode conhecer, por exemplo, a proposição "Ao amar a Deus tenho maior alegria do que em amar todas as coisas temporais" sem ter a experimentado o ato, e, por essa experiência deve possuir a virtude do amor a Deus.

\section{Conclusão}

A título de conclusão exponho algumas observações do exposto acima.

(1) O tema sobre a relação entre prudência e virtudes morais está inserido em uma questão bem mais ampla que diz respeito à conexão das virtudes. Sublinho que em todo o recorte, como é o caso deste texto, ficam de

\footnotetext{
35 OTh VIII, 374, 789 - 375, 798: "Quinta conclusio est quod prudentia quarto odo dicta, qua aliquis dicitur prudens quantum totum vivere, secundum quod includit notitias directivas omnium virtutum quae requiruntur ad perfecte vivere hominis, potest esse sine aliquibus virtutibus, et sine aliquibus non potest esse. Hoc patet, quia prudentia sic accepta incluit prudentiam tribos primis modis acceptam, et aliquia istarum prudentiarum potest esse sine virtute morali, sicut patet de duobus primis modis, et de tertio modo quantum ad aliquam prudentiam; et alia non, sicut patet de tertio modo quantum ad aliquam prudentiam".
} 
fora pontos que mereceriam maior atenção e aprofundamento. Todavia, tal empresa extrapolaria os limites deste artigo.

(2) Certamente Ockham não considera a noção de prudência de maneira unívoca, remetendo assim a certa ideia de "prudências". No entanto, essa ideia serve as seus propósitos.

(3) Quanto a relação entre virtudes morais e prudência (tratada na primeira e sexta conclusão), Ockham está em concordância com seus predecessores e, em geral, com toda a tradição, ao sustentar que não pode haver virtude moral e ato virtuoso sem prudência. Embora, na sexta conclusão, ele assevere que algumas vezes as virtudes morais podem existir sem a prudência no primeiro e segundo modo, isso não é problemático. De fato, transparece aqui a importância e prioridade que ele atribui à experiência (ponto apontado por Wood e que se presta a minuciosas investigações futuras).

(4) Quanto a relação entre prudência e virtudes morais (abordada da segunda a quinta conclusão), de acordo com Ockham, nos dois primeiros modos pode haver prudência (reta razão) sem que o ato virtuoso seja concretizado. O motivo disso é o de que, para ele, a liberdade absoluta da vontade pode fazê-la obedecer ou não ao ato proposto pelo intelecto. No terceiro e quarto modo, a prudência algumas vezes pode existir com ou sem virtude moral. Novamente em pauta o papel da experiência. É no interior dessas conclusões que a tese de Ockham vai sendo explicitada. Assim, da afirmação de que "não há virtude moral sem prudência, e, não há prudência sem virtude moral” surge a alegação segundo a qual a segunda parte da afirmação acima não é necessária, isto é, pode haver prudência sem virtude moral.

\section{Referências bibliográficas}

ADAMS, M. M. "Scotus and Ockham on the connection of the virtues". In: Honnefelder, Ludger; Wood, Rega and Dreyer, Mechthild (eds.). John Duns Scotus: Metaphysics and Ethics. Studien und Texte zur Geistesgeschichte des Mittelalters, 53. Cologne: E. J. Brill, 1996, p. 499-522. AGOSTINHO. Livre Arbítrio. São Paulo: Paulus, 1995. 
ARISTÓTELES. Ética a Nicômaco. São Paulo. Nova Cultural, 1991. CRISTÓBAL-SEBASTIÁN, A. S. Controversias acerca de la voluntad desde 1270 a 1300: Estudio histórico-doctrinal. Madrid: Editorial y Librería Company, 1958.

GUILLELMI DE OCKHAM. Quaestiones in librum tertio sententiarum (Reportatio). In: Opera Theologica VI. Ed. Kelley, F. et Etzkorn, G. (eds.). N. Y.: Cura Instituti Franciscani, Universitatis S. Bonaventure, St. Bonaventure, 1982.

. Quaestiones variae. In: Opera Theologica VIII. Ed. Kelley, F; Etzkorn, G. et Wey, J. (eds.). N. Y.: Cura Instituti Franciscani, Universitatis S. Bonaventure, St. Bonaventure, 1982.

. Quodlibeta septem. In: Opera Theologica IX. Ed. Kelley, F; Wey, J. (eds.). N. Y.: Cura Instituti Franciscani, Universitatis S. Bonaventure, St. Bonaventure, 1980.

HOBUSS, J. "Sobre a conexão das virtudes em Tomás de Aquino". In: Dissertatio, n. 11 (2000), p. 171-183.

INGHAM, M. E. "Practical Wisdom: Scotus's Presentation of Prudence." In: HONNEFELDER, L.; WOOD, R. and DREYER, M. (eds). John Duns Scotus: Metaphysics and Ethics. Studien und Texte zur Geistesgeschichte des Mittelalters, 53. Cologne: E. J. Brill, 1996, p. 551-571.

KENT, B. "Rethinking Moral Dispositions: Scotus on the Virtues". In: Williams, Thomas (ed.). The Cambridge Companions to Scotus. New York: Cambridge University Press, 2002, p. 352-376.

LANGSTON, D. C. "The Aristotelian Background to Scotus's Rejection of the Necessary Connection of Prudence and the Moral Virtues”. Franciscan Studies, Volume 66 (2008), p. 317-336.

LOTTIN, O. "La Connexion des Vertus chez Thomas d'Aquin et ses Prédécesseurs". In: Psychologie et Morale aux XII et XIII Siècles. Louvain: J. Duculot, Éditeur, 1949, p. 195-252.

- "Les Débuts du Traité de la Prudence au Moyen Âge". In: Psychologie et Morale aux XII et XIII Siècles. Louvain: J. Duculot, Éditeur, 1949 , p. 253-280.

SUK, O. "The Connection of the Virtues According to Ockham". Franciscan Studies 10 (1950), Part I: 9-32. Part II: 91-113. 
WOOD, R. Ockham on the Virtues. Indiana: Purdue University Press, 1997.

E-MAIL: pedroleite.pro@ig.com.br

RECEBIDO: Agosto/2012

APROVADO: Novembro/2012 